\title{
An Empirical Study on English Writing Based on the Input of Textual Recitation
}

\author{
Qunying Cao \\ School of Foreign Languages \\ Xiangnan University \\ Chenzhou, Hunan, 423000, China \\ 317012866@qq.com
}

\author{
Wuyun Xiao* \\ Development planning office \\ Xiangnan University \\ Chenzhou, Hunan, 423000, China \\ (Corresponding Author)
}

\begin{abstract}
How to improve students' writing competence has always been the focus of foreign language circle. By utilizing recitation-input method, this paper conducts an empirical study on improving students' English writing. The result indicates that recitation-input me thod can effectively improve students' English composition scores and their ability in language input and application with proper reciting methods and suitable monitor means on the basis of using appropriate recited materials.
\end{abstract}

Keywords—textual, Recitation-Input, English writing, training

\section{INTRODUCTION}

Writing competence is one of qualities for English learners. The goal of foreign language teaching is to cultivate students' ability to communicate in foreign languages. In order to achieve this goal, students need to be exposed to target language a lot so that they can have enough input by getting target language's materials extensively with receiving and perceiving information. In addition, after information storage, students should edit, sort out, internalize and organize the input so as to exchange information and express ideas with various output and reuse. Among all the input methods, recitation is definitely the best way, which is also the key for language acquisition and the shortcut to master a foreign language. As a Chinese saying goes, if you have recited thoroughly 300 Tang poems, even when you cannot write the poem, you will at least chant some, which illustrates the importance of recitation input.

However, it is still extremely hard for many college students to write English composition. Some of them don't know how to start writing; others regard their compositions not as the English writing. They have learnt English in primary school, junior high school as well as senior high school, thus they have basic language foundation for English learning and their vocabularies and grammar sense can also assure their ability of expressing their own thoughts. Yet these problems still exist. The reasons can be concluded from the following aspects: firstly, college students are short of language knowledge storage and lack writing knowledge which results in the failure to express their thoughts in English usually used by native speakers, that is to say, they use the wrong expressions that they consider as correct. Then how can we help them enrich their writing language expressions and enhance

This paper is phased achievement of the project of "The 12th five-year plan for education": "Study on multi-dimensional cognitive and practical analysis of emotional barriers on recitation input in foreign language learning.” (Hunan Education Discipline [2012] No. 009) language input to fundamentally overcome the negative transfer, and ultimately improving their English writing?

From the perspective of second language acquisition, this paper intends to further study the effective application of recitation input on improvement of students' English writing and to make them overcome the influence of mother tongue through writing course and express ideas more fluently in target language.

\section{Theoretical BACKGROUND OF ReCitation InPUT}

Students are unable to succeed in foreign-language learning without immersion in a large amount of target language's materials or the input of relevant knowledge. Without those, foreign-language learning becomes water without a source and a tree without roots, which means students fail to have effective output of information. Krashen proposes input hypothesis of second language acquisition theories, and in his opinion, as long as there is substantial input information, learners can have output when the accumulation of target language's material is sufficient[1]. Meanwhile, recitation is an effective method for processing a large number of centralized and intensive language input. The recitation of target language's materials can provide output information for learners, who are capable of expressing themselves in natural and fluent target language by internalization of recited materials after imitation and utilization in various ways. Krashen argues that language acquisition is accomplished by the language input and the main teaching method should concentrate on the best language input for students so as to promote their language acquisition[2]. The four features of optimal input are stated as follows: (1) comprehensible; (2) relevant; (3) ungrammatical; (4) abundant. In other words, in terms of degree of difficulty, the chosen materials should be easier than usual ones, therefore, the materials can be acceptable and understandable, which benefits for the output of writing, since "the ability of reuse (speaking and writing) is generated on the basis of comprehensible input."

Sinclair, a linguist, also has his own opinion. He regards language as not only a analyzable system which is based on grammar, but also a formulated system which is based on memory[3]. Hence, the importance of recitation language input on vocabulary acquisition speaks for itself. The organization of a text is dependent on the elements like words, phrases and 
sentences, as a result, these elements become "formulated phrases". If students can memorize them well, they can use these elements, which is why recitation language input becomes important way for vocabulary acquisition. At the same time, another linguist Ellis proposes a hypothesis that the frequency of language input is a decisive factor for language acquisition [4]. His hypothesis is based on the function of language input, drawing a conclusion of four functions of input. One of the functions is that learners can realize the gap between the contents of what they want to express and of what they actually express by input, therefore they will pay much more attention to the study of language input.

\section{AN EMPIRICAL STUDY}

\section{A. Subjects}

The subjects are 100 non-English majors from two classes of Xiangnan University entering college in 2014. Class one is clinic major and class two is medical image major. Among 100 subjects, there are 60 males and 40 females. The age of all subjects is between 18 and 20, with an average age of 19 years old. Class one is the experimental class, and there are 50 students including 22 females, who received training of recitation input during their English learning. Class two is the comparative class, and there are 55 students including 19 females. The result of statistics of scores of college entrance examination indicates that there is no significant difference between two classes $(\mathrm{P}>0.05)$.

\section{B. Hypothesis}

Recitation Input can improve students’ writing competence.

\section{Implement on Students' Recitation Input Training}

Experimental class and comparative class have four classes every week. In the light of routine teaching, teachers interpreted the writing course and finished exercises according to the textbook in comparative class, while in experimental class, teachers applied textual-recitation-input method so as to complete the training of writing thesis.

The procedure as follows:

1) The plan and requirement of illustration on recitation input: teachers sent out a recited textual material every week. The whole class was divided into 10 groups (five students a group), and there was a group leader in each group, who checked the reception situation every Sunday evening. The result was presented as four grades covering excellence, fine, qualified and unqualified which was then given to teachers. Teachers examined the recitation situation randomly during the class, the result of which accounts for the usual performance.

2) Assignment based on different recited materials measuring by proper methods:

\section{a) Imitated writing}

When reciting, students are required to notice some details of the materials as well as the application of collocations and idioms and fixed phrases. They are also asked to imitate those applications without worrying about the grammar issues. In this way, students can be familiar with imitation and they can write freely without too much hesitation.

\section{b) Proofreading}

On the basis of recitation of materials, teachers can provide a relevant short passage with some grammatical mistakes for students to identify and correct. According to Krashen's Monitor Hypothesis, the language knowledge which is acquired with consciousness plays a role in monitoring and editing, which can be used to examine and correct the output. The method can solidify and improve students' overall language capability effectively, thus further actively facilitating their conscious recitation input.

\section{c) Back translation}

The students are given Chinese translation of recitation materials, and they are requested to translate Chinese into English. After finding differences between translation and original materials by comparison, they recite the materials so that they have a better understanding on the idiomaticity and the beauty of the original ones so as to have better communication in target language.

\section{d) Adapting or retelling}

Students are asked to adapt the materials by changing the view of person or to adapt the materials according to key words in their own words. They also need to retell the materials, which they can prolong or shorten in a proper way based on the structure or key words. Students can creatively use their own words through adaptation or retelling to interpret recitation materials by refinement, processing, abstraction and summary.

\section{3) The feedback and comments on their assignment}

After feedback and comments, students saw their progress as well as their shortcomings. Meanwhile, the performance of their homework is recorded to the usual performance scores, which activates their motivation on employment of recitation input method.

\section{Experimental Result}

The experiment was conducted from March, 2014 to June, 2014, which lasted for 16 weeks. The data collection contains two parts: one is data statistics of composition scores of both experimental class and comparative class before the experiment; another is data statistics of composition scores of both experimental class and comparative class after the experiment.

The compositions were read over and given scores by two teachers, meaning that one paper was given two scores by different teachers. The average score was the final score, whose full mark is 15 points according to scoring criteria of CET 4 and CET 6. The two teachers were responsible for the scores before and after experiment.

In addition, we have interviewed students about their opinions on recitation input after the experiment. We applied SPSS 17.0 to analyze these data in order to find out whether there is a noteworthy difference between experimental class and comparative class after the experiment. 
The result as follows: there is a noteworthy difference of composition scores between experimental class and comparative class. Before the experiment, the average score of experimental class is 6.3 and comparative class is 6.5, which shows little target language difference $(\mathrm{P}>0.05)$. But after the experiment, the average score of experimental class is 7.8 , while comparative class 6.7 , which has noteworthy difference $(\mathrm{P}<0.05)$.

\section{E. Discussion and Analysis}

As for the reason of marked difference on composition scores between experimental class and comparative class, the analysis and discussion are as follows:

\section{1) Proper textual materials in target language}

We select proper materials which activates students' interests of recitation. In terms of materials, we adhere to the following principles: first, the selected themes which can activate subjects' curiosity, imagination and interest subjects, such as Dangers to the Environment/ Internet Helps Solve a Medical Mystery; secondly, the selected materials are close to subjects' daily life., In consequence, subjects can get inspiration and relate to the content and even can learn from it. For example, How to Make a Good Speech in English/ The Importance of Self-confidence / Which Deserves Priority Specialty or Scores/What is Success/ Part-time Jobs/Choosing Careen/ Success Is Measured in terms of Money/ TeacherStudent Relationship, etc. Thirdly, the selected topics are the hot issues that people concern about currently. The materials are selected from recent original books and magazines which provide latest and authentic materials. Fourthly, the proportion of new words is controlled about $5 \%$, a little more difficult above subjects' current level. Finally, the genre of materials is various. In consequence, the subjects not only increase their interests, but also comprehend and master various genres, including description, argumentation, exposition and narration. Since we have followed these principles, it is easier for subjects to have sense of intimacy and acceptance, which in turn activates their initiative. And ultimately they can insist on recitation and fulfill the assignments.

\section{2) Enhancement on application of recitation input}

"The criteria of success for English learners is not only up to how much information they have memorized, but also dependent on whether they can use what they have learnt creatively to express in oral or written English, that is to say, they are not only able to cognize, but also to internalize the language knowledge they've learnt, on the basis of analysis, comprehension, judgment, reconstruction and recreation[5]. " Subjects have recited plenty of materials in target language. If these materials are not used in practice, the recitation has the sole function of input without the output function. Through many kinds of training methods such as imitated writing, proof reading, back translation, adapting and retelling, subjects can use the original materials creatively. According to their own experience, subjects are able to apply known vocabulary, grammar, and key words. Using original materials creatively to consolidate, enhance and internalize their language knowledge, subjects can be more sensitive to the language phenomena of target language, which in turn enhances the language applying competence.

3) Transformation from explicit knowledge into implicit one after recitation input

According to Canadian linguist Bialystock's study on second language acquisition theory model, he divides language into two types: explicit and implicit linguistic knowledge[6]. Explicit knowledge refers to knowledge existing in learners' consciousness including knowledge of grammar and idioms. This knowledge can be verbalized clearly by learners. Implicit knowledge refers to those internalized knowledge, existing in learners' sub-consciousness, which enables learners to express in English freely, but may not clearly. Explicit knowledge is very limited for the surface input. Only if we input explicit knowledge constantly can it be changed into implicit knowledge. And when we accumulate the implicit knowledge, we can improve the sensitivity of target language and enhance the language sense and our consciousness. The input of language should be filtered by the brain, that is, internalization and selection with sub-consciousness before it can be taken in. Then it can enter the output procedure after organization and edition. In addition, recitation is an effective way of transformation from explicit language knowledge to implicit language knowledge. Since all the recited materials are selected carefully by the teachers, learners are interested in the content which is close to their daily life. Furthermore, learners can identity word meanings very quickly, understand relevant methods of word and textual structure after reciting comprehensible materials with moderate difficulty. Through application training, learners can improve their languageconcept competence and processing strategy, which facilitates explicit knowledge to enter in language organization system with internalization and compatibility. When learners use target language, they can extract it very quickly at any time, which forms automatic language output model. With the output, they enhance their language sense and use the language knowledge more frequent in target language, like idioms and contexts, which makes up the defects on the shortage of natural environment of target language.

\section{CONCLUSION}

Recitation input helps students enhance textual comprehension, memorize beautiful language and creatively use vocabulary in the recited texts. Students who use fixed phrases during their writing can make composition coherent and shorten the time of writing. Chinese students lack enough writing input, especially the internalized implicit knowledge, while recitation input can be regarded as an optimal input [7]. However, only recitation is not enough, we also need to apply recited materials in proper ways. And in this way, recitation input can promote acceptance, comprehension and intake of the materials. As a consequence, students' language input can be truly enhanced and their implicit knowledge can be broadened. Meanwhile, they can eliminate the disturbance of mother tongue and overcome the negative transfer during English writing. Ultimately, students can master target language like "dismember an ox as skillfully as a butcher", that is to say they can master target language with ease and skill as well as improve their writing competence. 


\section{REFERENCES}

[1] Stephen D. Krashen Applicants of Psycholinguistic Research to the Classroom, Washington. D. C. Methodology in TESOL, 1987(3).

[2] Stephen D. Krashen Principles and Practice in Second Language Acquisition. Prentice-Hall International, 1987.

[3] Sinclair, J. Corpus, concordance, collation [M]. Oxford: Oxford University, 1991.
[4] Rod Ellis. Second Language Acquisition, Oxford: Oxford University, 2002.

[5] DING Yan-ren. The Function of Recitation Input on English Writing[J]. Foreign Language World, 2001(3).(In Chinese)

[6] Bialystock, E.A Theoretical of Second Language Learning[J]. Language learning, 1978(28).

[7] DENG Li-ming. Concerns on Elimination of Negative Transfer in Recitation Input [J].Foreign Language Teaching, 2001(4). (In Chinese) 